\title{
The Case Studies of Depression among Migrant Children and Left-Behind Children during China's Rapid Urbanization
}

\author{
Zheng xiaoxiang \\ Business School, Yunnan University of Finance and Economics \\ Kunming, Republic of China \\ zhengxx1978@ynufe.edu.cn
}

\begin{abstract}
With the rapid development of urbanization in china, the probability of depression among MC and LBC remains increasing. The prior study indicates that migration was main factor for Children's depression. Based on the three cases, the author concludes the lack of social capital (family care, friendship and teacher's care) might be associated with an increased risk of depression in MC and LBC in china. Not only in that China's traditional social network relationships has been ruined and the interpersonal relationship becomes weaker, but also there are long learning hours, low social capital and the exam stress among MC and LBC.
\end{abstract}

Keywords-rapid urbanization, depression, migrant children (MC), left-behind children (LBC).

\section{INTRODUCTION}

There was news that jumping without any symptom that a nineteen years old student lived before he died by Southern Weekend on March 27, 2014. I feel very sorrowful and deeply regret about his death. Why did he commit? The possible reason lies at that he suffered from depression. In 20116.87 percent of the total population suffered from depression in China, whose common symptoms are sleepy disorder, emotional downcast and pessimistic and despair. Yan Wenwei, a professor at Shanghai Psychopath Research Institution, said that thirty percent of patients committed suicide. According to the Lancet, it estimated that in China sixty-one million people that suffered from depression in 2012, and the number increased year by year. To the end of 2020, depression will displace cancer to become the second disastrous disease of human being. For that depression patients need to take medicine for many years, the local government has to bear a large sum of money. In the European Union there are over one hundred eighteen billion dollars per year for depression affected patients, who are more likely to commits to suicide. There are twenty-two million people that suffered from depression in USA, of whom one person commits suicide every thirteen minutes.

It is estimated that around 58 million children under 19-years-old are left behind at rural hometowns by their parents in 2010, and nearly 20 million MC are accompanying their parents to relocate in cities. The study indicated that $\mathrm{MC}$ and $\mathrm{LBC}$ are at a greater risk of mental health and behavior problem (Guo, Chen, Wang, 2012). According to the news of Chinese Jiao tong Daily, at Spring Festival of 2014 there were twelve hundred eighty-six children living in the Ake Middle School of BaMei County of Yunnan Province, over eighty percent of whom were left behind by their parents. The children and parents get together only once a year, so many of children were anxiety, weariness and infantile autism. They were so shy and cowardly in that they always lived with their grandfathers and grandmothers. Someone even took sleeping pills to suicide in the bedroom. In order to help them to live together with their parents, the government of the Chinese Transportation Department brought some children to the Dongwan City of Guangdong Province in which their parents worked and lived. 


\section{Migration AND MENTAL HEAlth IN ChinA}

Urbanization is making rural villagers become urban residents. The rate of urbanization refers to the ratio of permanent resident population in the total population; however, rapid urbanization is a quick growth population and the expansion of the city space. According to the Fifteenth Conference of CCP, Premier Li Keqiang put forward the great plan of Chinese New Urbanization, that by the end of 2020, the rate of urbanization will reach about sixty-five percent, for which many problems need solving for additional one hundred million populations from rural to urban, for example, freshwater, shelters, transportation, education and medical treatment, the superimposed effect of which help increase the probability of depression in China. In 2014, President $\mathrm{Xi}$ Jinping expressed that rapid urbanization should been denied and new urbanization to be based on human rights.

The overwhelming majority of studies between global immigration and mental health conclude that the migration and the related experiences of insecurity, along with the main risk factor is the loss of accustomed social networks, which is harmful to psychological health. For example, social capitals are associated with the low depression among older Chinese and Korean immigrants in the USA (Kim \& Auh, 2013). The Vietnamese-immigrants have higher rates of anxiety-depression than compatriots in low-middle income countries and lower rates than populations in host high income countries (Liddell \& Chey, 2013).However, other studies suggest that since the migration could enhance economic status level and increase the living opportunities; this may lead to improved psychological health. I agree to the former view. Although the migration in China could advance the economical level and increase material income, Rural-to-Urban migration is liable to cause be anxiety and depression because of low social capital and low social support.

\section{III.SOCIAL CAPITAL AND DEPRESSION}

According to two different approaches of social capital, the first approach is influenced by Putnam (1995), the structural component is networks, association and behaviors; the second approach is influenced by Bourdieu (1986), the cognitive component is subject and intangible aspects, trust and norms, support or resources.

In China, social network relationship mainly includes family and relations, friends and teachers' care. With the development of China's rapid urbanization, the prevalence of depression was 10.9 percent among RC (rural children), 19.7 percent among MC (migrate children), and 14.3 percent among LBC (left-behind children). To comply with the national definition of a migrant population, the LBC was defined as "children under 19 who have been left behind at their original residence while one or both parents migrate into other places for work and live separately for at least 6 months". MC is defined as "children under 19 who have left their original residence and migrated to big cities for at least 6 months." RC refers to children fewer than 19 living with both parents at their original residence. The result indicates that Internet addiction might be associated with an increased risk of depression in $\mathrm{LBC}$, and migration was an important risk factor for child depression (Guo, Chen, Wang, 2012).

The children of Rural-to-Urban Migrants had high emotion and effect of stereotype; however they were discriminated and scorned by urban children in that their parents migrated from rural to urban (Chen, Guan, 2013). There was a relationship between rumination and anxiety and depression of children, so it can forecast procrastination status through rumination (Kang, Mu, 2013). A nineteen-year-old youth had been found that he had been in depression and rumination, but nobody would take care of him. New Urbanization depends on residents' freely migration, medical treatment and social welfare. With economic development, personnel rights protection and freedom enlargement, new urbanization will be operated trouble-free (Yang, 2014). However, there are so many Rural-to-Urban Migrants who face poverty and unemployment, over-crowdedness and low social welfare. On September 12, 2014 in Kunming, a fire disaster befell in rental housing, leading to two children's death and one severely burned. The children were left without supervision because their parents had to work outside for a long time every day, and they only had eight hundred Yuan per month 
and fourteen Yuan per day including three hundred eighty Yuan on rental fee. Nowadays, the rapid urbanization leads to a great gap between rich and poor, and slums have come into being for Rural-to-Urban Migrants in China.

These viewpoints indicate the causes that lead to depression of $\mathrm{MC}$ and $\mathrm{LBC}$ in China. However, different viewpoints will be put forward on the cases, expressing the propositions during Chinese rapid urbanization.

\section{IV.. CASE Study}

\section{A.A nineteen-year-old youth depression and suicide}

He Shuqing was born in a village named Chengbei of Pingjiang County Wenzhou city. In his childhood his parents migrated into the Town of Aojiang County. There were no other activities except for video games, and boys played video games all day and night. Without middle school, he had to migrate into the town of Xiaozheng for learning to attend Middle School. Here he had no old friends, and he was discriminated and scorned by his classmates while he played in the class programmer. Before he died, he lonely walked and talked by himself disorderly in that he was so long for friends. In order to make money for clothes and food, his parents worked long hours per day and didn't take good care of him. So he deeply demanded parental love and care. Once his English teacher deprived him of writing in a test paper, so which directly led to his suicide. Without any care and friendship, no outlets for unhealthy emotions, long-hour learning and the pressure from Gaokao, all these resulted in his death. The compensation is five hundred eighty thousand Yuans offered by the Xiaozheng Middle School on April, 2014. Can it recover the children's life? Never!

He Shuqing and his classmates learned from six o'clock in the morning to ten in the evening, at an average of $13 \mathrm{~h}$ a day, except for weekend and holiday. He Shuqing had a dream that one day he would pass Gaokao into a famous college, but as a matter of fact, his mark was at a medium in his class. So stress of the Gaokao and long-hour learning combines to make him deeply depressed.

One Dimensional Man Studies in the ideology of
Advanced Industrial Society, in his book Herbert Marcuse points out that industrial civilization changed human beings into animals without spiritual activities and affection, owning simplified technology and only pursuing for fame and money, a transforming and alienation of human being under the pressure of living.

The first proposition we put forward is that during the rapid urbanization lack of friendship, the long learning hours and the stress from the Gaokao increase the likelihood of depression and suicide in MC.

\section{B.A young girl committed suicide as a thief by her neighbors}

Rapid urbanization ruins some Chinese advanced culture, and many residents don't visit their neighbors or even know each other. Even visiting neighbors is restricted in some cities. A young girl who visited her neighbors in the Nanning City of Guangxi Province on June 29, 2013, was abused because she got incorrectly into one stranger's door. For the cause that the householders were stolen several months ago and mistook the young girl for the thief, be naked as a compensation for the loss. The poor young girl had to promise and pay for it, however she was depressed and committed suicide by taking pesticide after she came back home. The two criminal suspects had been sentenced to prison for eight years and three years, and compensated four hundred fifty thousand Yuan to the family of the dead. In order to avoid the prevalence of suicide, the Chinese culture should include the friendship of neighbors along with the development of rapid urbanization.

The second proposition is that during rapid urbanization living without social relationship increases the likelihood of anxiety and depression in MC.

\section{A thirteen-years-old boy was depression and infantile autism}

Shang Xiaoxiang was born in 2001 , as a son of a professor of Wuhan University. When he was three years old, his handsome and clever attracted many people. His grandmother took care of him. However his grandmother died in 2007. At the same time, Professor Shang migrated to Chengdu for teaching, so the poor boy was left behind in his 
maternal grandfather's family, which located in a small mountain village of the western Hunan Province. His maternal grandfather got up early and returned back home late every day in that there was a sizeable chunk of land. The little boy always played alone, bullied by neighbors' children. One day Professor Shang was told that the boy was wronged. The professor immediately lay down his business and took back his child. The poor boy couldn't speak clearly or recognize his father and his mother. He was diagnosed as infantile autism. The parents were extremely grieved and tried all their best to bring up his children. As a left-behind child, Shang Xiaoxiang lacked parental love and care, and that there was no kinder-garden in the rural.

The third proposition is that lack of family care, friendship and compulsory education increase the likelihood of depression and infantile autism in LBC.

\section{DisCUSSION AND CONCLUSION}

The New Urbanization doesn't change farmers rapidly to urban residents, but supply them with shelters, education and medical treatment and social warfare. If child and youth don't own basic rights and powers, they will become anxious and depressed. In western developed countries the urbanization rate is eighty percent, however, slums hindered social economic progress, which is not a successful model for China. Nowadays, there are many shelters for low income family in city, but these cheap renting houses

\section{REFERENCE}

[1] Bum Jung Kim, Erica Auhm, the impact of social capital on depression among older Chinese and Korean immigrant: similarities and differences, Aging \& Mental Health, 2013, Vol.17, 844-852.

[2] Belinda Liddell, Tien Chey, Patterns of risk for anxiety-depression amongst Vietnamese-immigrants: a comparison with source and host populations, BMC Psychiatry 2013, 13:329.

[3] Chen Jiejian, GuanJian, Effect of stereotype of Rural-to-Urban Migrants' children, Social Psychology Study, February, 2013.

[4] Lu li, Hong-mei Wang, Xun-jun ye, the mental health status of Chinese rural-urban migrant workers: comparison with permanent urban and rural dwellers: Soc Psychiatry Psychiatric Epidemiology2007; 42:716-722. exclude to Rural-to-Urban Migrants. In order to guard against the gap between rich and poor, two suggestions have been put forward that the first one is to begin registering real estate and supply the immigrants with cheap renting houses; the second is to levy a tax on householders that their per area is over 70 square meters .

Supply more public places for urban residents and encourage more children and youth to take part in physical and culture activities. There is a Chinese saying by Guanzi that if there are so many grains in the store, people would be polite and honest, and if human beings have fresh food and good clothes, they are honorable and shame free. People demand not only material civilization, but also spiritual civilization. For example, they need singing 、 dancing 、 playing table tennis、Majiang、skating、 handwriting、 Taiji Quan. It is harmful for their eyes while child and youth learn and watch TV, play games at home all the time. I have witnessed that in the Visual Department in hospital, so mangy patients were playing games on the mobile telephone, while waiting for doctors. In order to prevent child and youth from indulging in TV programmer and video games, electric supply should be restricted and be hold down for two hours in the weekend. We have to bring child and youth to play with their friends outside.

[5] Jing Guo, Lichen, Xiaohua Wang, The relationship between Internet Addiction and Depression Among Migrant Children and Left-Behind Children in China, Cyber psychology, Behavior and Social Networking,volume 15,number 11,2012.

[6] Kang Jing, Mu Jing, the relationship between

rumination and procrastination status and anxiety and depression in students, Social Psychology Study,February,2013.

[7] Xi Yihao, Jumping off a building without any symptom, and a nineteen-year-old-student lived before he died, Southern Weekend, March 27, 2014.

[8] Yang Junfeng, the investigation and thinking of the Chinese villages in my eyes, and when I came back home at Spring Festival in 2014, Southern Weekend, March20, 2014. 